\title{
Autosomal dominant inheritance of Weaver syndrome
}

\author{
Alan Fryer, Colin Smith, Lewis Rosenbloom, Trevor Cole
}

\begin{abstract}
Most reports of Weaver syndrome have been sporadic cases and the genetic basis of the syndrome is uncertain. This report of an affected father and daughter provides evidence for autosomal dominant inheritance.

(F Med Genet 1997;34:418-419)
\end{abstract}

Keywords: Weaver syndrome; autosomal dominant inheritance

Weaver syndrome (WSS) was first described in $1974^{1}$ and is characterised by accelerated growth, advanced bone age, typical facial appearance, digital abnormalities, and developmental delay. The syndrome has been recently reviewed by Cole et $a l^{2}$ Most reports have been sporadic and the published familial cases have been difficult to interpret owing to paucity of clinical details or absence of photographic support. Some families have been reported as showing autosomal recessive inheritance and four families have so far been reported as showing autosomal dominant inheritance. Of these dominant cases, however, Cole et $a l^{2}$ considered case 2 described by Majewski $e t a l^{3}$ as being more typical of benign familial macrocephaly and the information in Ardinger $e t a l^{4}$ and Stoll et $a l^{5}$ insufficient to confirm or refute the suggestion that the two mothers showed a mild expression of WSS.

The most recent report of autosomal dominant inheritance by Dumic et $a l^{6}$ describes non-identical twins (brother and sister) with features suggestive of Weaver syndrome, but no early photographs were included. The mother of the twins was said to have been a big baby and to have had some of the clinical features of her children, such as macrocephaly, long philtrum, large ears, hoarse voice, prominent finger tip pads, deep set nails, hyperextensible fingers, and hyperhidrosis of the palms. However, no photographs were included and therefore the diagnosis in this family remains open to debate.

We present a family in which a child and her father both have features of Weaver syndrome, thereby providing convincing evidence of autosomal dominant inheritance.

\section{Case reports}

Case 1, the third child of unrelated parents, is female and was born at 42 weeks' gestation by elective caesarean section, weighing $4100 \mathrm{~g}$ (90th centile). During the pregnancy, there was relatively little fetal movement and she main-

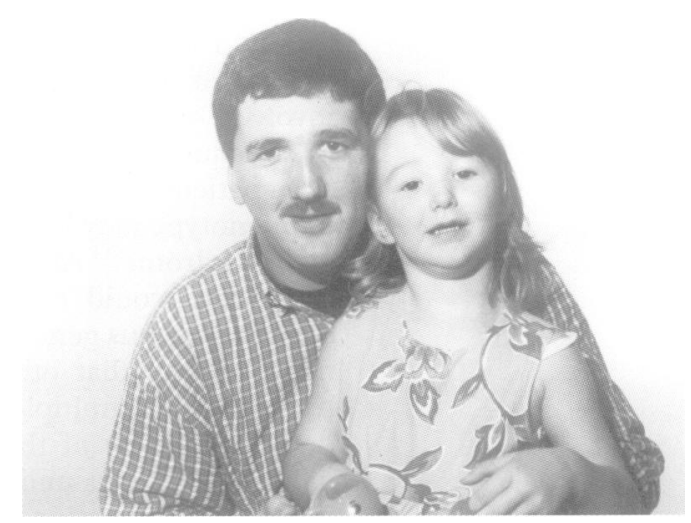

Figure 1 Appearance of case 1 at 3 years of age with her father (case 2).

tained a persistent breech position. After birth she was hypotonic and feeding was difficult.

She was delayed in both her gross motor development (sitting unaided at 9 months, walking at 20 months) and language development and at the age of 25 months she remained somewhat floppy and clumsy, was only just beginning to put words together, and was attending a special needs nursery.

Her growth in the first two years of life had been dramatic. At 19 months, her weight was $19 \mathrm{~kg}$ (>>97th centile) and height $93 \mathrm{~cm}$ ( $>97$ th centile, height standard deviation score +3.8 ) with head circumference $48.5 \mathrm{~cm}$ (50th centile). This gives a weight for height index of $133 \%$. There was increased leg length compared to sitting height. At this age, her bone age was 3 years 6 months using Greulich and Pyle standards. By the age of 22 months, her height had increased to $98.8 \mathrm{~cm}$ (height SDS +4.8) and weight to $19.5 \mathrm{~kg}$ (weight for height index 123\%). By 34 months, her height was $111.6 \mathrm{~cm}$ (height SDS +5.4) and weight for height index was now $116 \%$.

Initially a diagnosis of Sotos syndrome was suggested but the facial features, the weight to height ratio, and the flat and rather deep set nails suggested a diagnosis of Weaver syndrome. She does not have other features of Weaver syndrome, such as contractures, prominent finger tip pads, or overlapping toes. Her appearance at the age of 3 years is shown in figs 1 and 2 , along with her father (case 2).

Case 2, the father of case 1 , is reported to have weighed $5400 \mathrm{~g}$ at birth. He is the third of a sibship of seven and his father was aged 25 years and his mother 24 years at the time of his birth. He was said to have been a very large child. His adult height is $185 \mathrm{~cm}$ (90th centile), which is taller than the rest of his six sibs (two brothers and four sisters; the tallest of these is a brother at $173 \mathrm{~cm}, 25$ th centile) and both of
Received 1 August 1996 Revised version accepted for publication 2 December 1996 


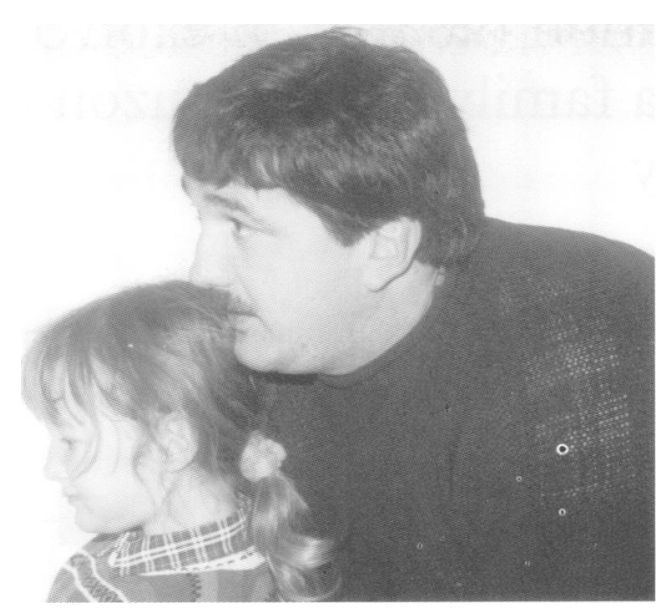

Figure 2 Profiles of case 1 and case 2.

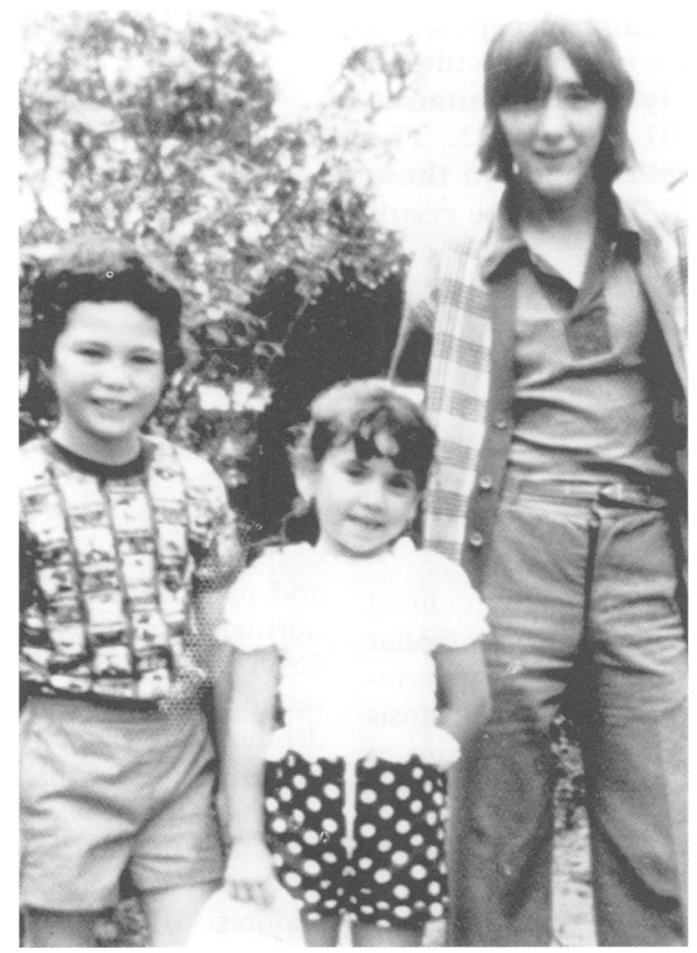

Figure 3 Appearance of case 2 (boy on the right of the photograph) during childhood.

his parents are said to be approximately $165 \mathrm{~cm}$ tall. He has a very large head (OFC $61 \mathrm{~cm}$ ) and large hands ( $21 \mathrm{~cm}$ total hand length). He went to a normal school and now works as a builder's labourer. His facial appearance is similar to that of his daughter and fig 3 illustrates his appearance on one occasion during childhood. $\mathrm{He}$ also has deep set nails (fig 4) but no history of camptodactyly or other digital features of Weaver syndrome.

\section{Discussion}

The dramatic pattern of overgrowth shown in case 1, together with the facial features and advanced bone age, allow a diagnosis of Weaver syndrome. The features in her father (case 2) strongly indicate that he too is affected. This

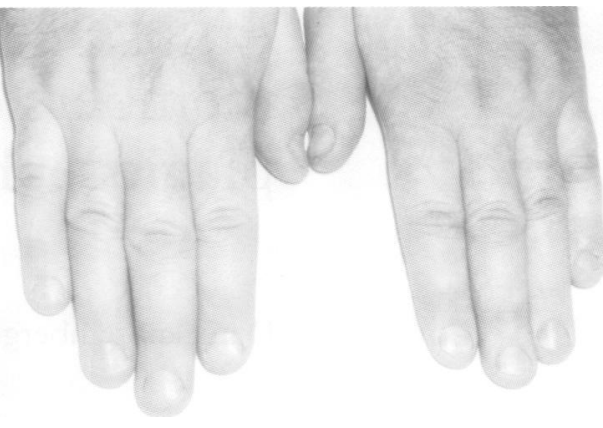

Figure 4 Appearance of the finger nails of case 2.

family provides convincing evidence of autosomal dominant transmission of Weaver syndrome with case 2 probably representing a new mutation.

All of the previous reports of autosomal dominant inheritance have been open to doubt and, as most cases of WSS are sporadic, other mechanisms such as uniparental disomy (UPD) are possible. There are no published data on studies looking for UPD in Weaver syndrome, though no evidence has so far been forthcoming in Sotos syndrome, ${ }^{7}$ an overgrowth syndrome with which WSS may be confused. Most cases of Sotos syndrome are also sporadic and the most likely mode of inheritance in the familial cases is autosomal dominant. $^{8}$ In another overgrowth disorder, Beckwith-Weidemann syndrome (BWS), which exhibits autosomal dominant inheritance in approximately $10 \%$ of cases, UPD has been identified and parent of origin effects have also been observed. ${ }^{9}$ In our case of Weaver syndrome, transmission has been from father to child and if the previous reports are accepted as dominant families with WSS, the transmission has been from mother to child. Therefore, there is no evidence so far of any parent of origin effect in the transmission of the WSS phenotype.

Weaver syndrome may thus be inherited as an autosomal dominant trait and the discovery and publication of other families may allow further clarification of its genetic basis.

1 Weaver DA, Graham CB, Thomas IT, Smith DW. A new overgrowth syndrome with accelerated skeletal maturation, unusual facies and camptodactyly. $\mathcal{f}$ Pediatr 1974;44:54752.

2 Cole TRP, Dennis NR, Hughes HE. Weaver syndrome. $\mathcal{F}$ Med Genet 1992;29:332-7.
Mele

3 Majewski F, Ranke M, Kemperdick H, Schmidt E. The Weaver syndrome: a rare type of primordial overgrowth. Eur F Pediatr 1981;137:277-82.

4 Ardinger HH, Hanson JW, Harrod MJE, et al. Further delineation of Weaver syndrome. $\mathcal{F}$ Pediatr 1986;2:228-35.

5 Stoll C, Talon P, Mengus L, Roth M, Dott B. A Weaver-like syndrome with endocrinological abnormalities in a boy and his mother. Clin Genet 1985;28:255-9.

6 Dumic $M$, Vukovic J, Cvitkovic $M$, Medica I. Twins and their mildly affected mother with Weaver syndrome. Clin Genet 1993;44:338-40.

7 Fullwood P, Smith M, Upadhyaya M, Cole T. A search for uniparental disomy in Sotos syndrome. Eur $\mathcal{f}$ Hum Genet 1996;4(suppl 1):144.

8 Cole TRP, Hughes HE. Sotos syndrome. F Med Genet 1990; 27: 571-6.

9 Elliot M, Maher ER. Beckwith-Wiedemann syndrome. $\mathcal{f}$ Med Genet 1994;31:560-4. 